\title{
Student Satisfaction and Learning Needs in Distant Education: Towards Lecturers' Pedagogical Strategies and Attitude
}

\author{
Sharifah Sariah Syed Hassan \\ International Islamic University Malaysia \\ Siti Rafiah Abdul Hamid \\ International Islamic University Malaysia \\ Rusmanizah Ustati \\ Language Department \\ IPGM Kampus Pendidikan Teknik, Bandar Enstek, Malaysia
}

Doi:10.5901/jesr.2013.v3n7p760

\begin{abstract}
Blended learning involves both traditional face to face classroom teaching and e-learning approach. To date, past research in Malaysia focused much on the effectiveness and acceptace of e-learning (Ndubisi, 2006); attitude towards e-MBA (Mahmod, Dahlan, Ramayah, Karia, Asaari, Muhammad \& Abu Hassan, 2005) as well as factors affecting students' willingness and commitment to use e-learning continuously (Ramayah, et. al.; 2010). However, the system can only be accepted by students when there are effective teaching strategies. Further, learning structure must be well-structured to enable students to persist and maintain their engagement in the e-learning environment. The present study has investigated student learning via the use of e-learning and face to face approaches. The major focus of this study was to examine the students' experiences and their level of satisfaction via quantitative and qualitative methods. Using self constructed questionnaire, the satisfaction of student learning is determined by the lecturer's teaching strategies and lecturer's attitude or awareness towards the whole concept of distant learning itself. The samples of the quantitative study involved 400 students majoring in English Language, Counselling and Islamic Education at one of the faculties in a Public University in Malaysia which was analysed using Multiple regression analyses. The qualitative study focused on interviews related to students' satisfaction based on Michael Moore's Theory of Transactional Distance related to lecturer and learning management system (LMS).

Findings from this study indicated satisfaction in learning at the University via blended mode of distant learning approach. However, some of the emerging themes from the interviews have further highlighted the issues and challenges in distant education.
\end{abstract}

Keywords: transactional theory, e-learning, blended learning, Learning management system, distant education

\section{Introduction}

Distant education evolves parallel to the advancement of technology. Previous years have shown the evolution of distant education as a second opportunity to learn via the use of postal correspondence, video, web based learning and blended mode of face to face with online approach. The success and failure of a program depend highly on the learning infrastructure, quality of support systems, content and assessment, and peer support networks (Areti, 2006; Moore, 1993). On the other hand previous researches have emphasized on interaction as the main predictor of a success online distant education. Literature has shown that student feedback is essential in providing information on the effectiveness of distant education. This is consistent with claims made by Biggs (2006) and Clayton (2004) who indicated that the feedback can provide important information on what works and which needs to be intervened.

Previous studies have addressed the effectiveness of distant education by evaluating the effectiveness of LMS (Khadijah, Siti Aswani, Mohd Nasir Ismail, 2012). Others include student satisfaction in learning at distant via on line (Walker, 2005). However, different learning management system will result in different feedback and satisfaction of learners. This study seeks to examine the effectiveness of distant education at International Islamic University specifically at the Institute of Education. The element of effectiveness was examined based on students' feedback of their learning 
experience using LMS and teaching strategies. Further lecturer's attitude in supporting the students is highlighted.

\section{Effective distant education: design and practice}

Moore (1993) emphasized much on interactions in online learning. He refers to three modes of interactions namely; student-student, student-content and student-teacher. These interactions predict the success of distant education as they allow students to share their knowledge, experience and thoughts in the collaborative learning environment. This teaching-learning embraces the constructivist approach of learning as proposed by Vygotsky (1978) in that learning takes place through interactions with others. This suggests that 'internal speech and reflective thought arise from the interactions provide the source of development of a child' (p. 35). Vygotsky has elaborated much on the concept of learning among children and their development. However, this theory has extended to distant education specifically online learning approach which caters adult learners through the social interaction networks.

The design of content and its interactivity relates to the use of technology namely Learning Management System (LMS). It allows collaborative tools such as forum, chat tools and others to ensure students can interact and collaborate to complete a project. Ineffective LMS will diminish student's motivation and to be persistent in learning due to the failure of student's communication, late feedback from the lecturers and difficulty to download files and content. Thus, it impedes student's autonomous learning in that students are unable to self regulate their own learning process. Lee and Lee (2008) have shown positive relationship between self regulatory and e-learning quality via LMS.

Teaching strategy is said to be the main predictor of effective e-learning or online learning and distant education (DeBourgh, 1999). Rosenberg (2001) and Garrison (2011) have elaborated on the importance of teaching strategies in elearning environment. They stressed on the need to strategise the effective method in delivering knowledge to the learners. These include support and teacher readiness to deliver the information online.

\section{Methodology}

The study utilized a triangulation approach where a survey was carried out among 400 samples from a teaching faculty in a Public University studying for bachelor degree in English language, counseling and Islamic Education. Student responses towards their learning satisfaction and experience were derived from a self constructed questionnaire. The dependent variable involved was student satisfaction and predicted by two variables namely; teaching strategies and lecturer's attitude or awareness towards distant learner. The detail of items is revealed in the following Table 1.0. In order to gain insight of the findings, two second year students (one male and one female) were interviewed. The interview sessions took place at the faculty. All the questions were based on student satisfaction toward the program. To be more focused, Moore's theory of transactional distant (1999) was used to underpin the framework of interactions in distant education. These questions were formulated with open ended format so as to allow students to elaborate further. The interview has been taped, transcribed and validated by the student.

\subsection{Analysis procedure}

Descriptive statistics are elaborated with mean and standard deviation to reveal the robust response and variation of the students' feedback. Despite the fact that the selection is based on purposive and convenient sampling procedure, the results have been addressed carefully by ascertaining the internal reliability estimates of the constructs investigated (Cronbach Alpa) and considering their significance as well. Linear regression was used to obtain the model fit using variance explain $\left(R^{2}\right)$. The probability of $p<.01$ was used to ensure high significant level for the relationships between independent and dependent variable. The interview was themed according to the interaction of student, lecturer and technology of LMS. These interactions signify the satisfaction of distant learners. Findings from both approaches were then triangulated (compared and merged) to ensure robust explanation.

\section{Results}

Findings from the survey revealed overall satisfaction on the distant education program, teaching strategies employed, and positive attitude of the lecturers. These were based on the students' responses whereby the mean distributions (5Likert scale) ranged from a low of 3.57 and a high score of 4.33. The lowest mean is revealed from 'refer student to the office when technical problems arise' (3.57). The highest mean score is revealed from 'good communication skills'. The 
distribution of data among 400 respondents is well dispersed of standard deviation from a low .491 to .898. Table 1.0 tabulates the means, standard deviations and detail of the items.

The overall satisfaction of distant education is explained by the following items; Blended mode is fascinating, Blended mode helps me to upgrade my skills in school, Blended mode helps me to learn effectively and Blended mode gives positive impact and Overall program is effective'.

The lecturer's attitude is explained by the following behavioural attributes: "Good communication skills, Refer student to office when technical problems arise, Provide announcement and update information and Prepare notes early'.

Effective teaching strategies are explained as follows: 'knowledge, good teaching strategies, good explanation, give immediate feedback online, give announcements and updates, content of teaching is parallel with course requirement, notes are suitable, and teaching is well structured".

These three factors namely overall satisfaction of distant education, lecturer's attitude, and lecturer's teaching strategies are analysed using linear multiple regression from the computed total mean score. Table 2.0 reveals the results.

Table 1: mean distribution of items

\begin{tabular}{|l|c|c|}
\hline \multicolumn{3}{|c|}{ Descriptive Statistics } \\
\hline \multicolumn{2}{|c|}{} \\
\hline Good teaching strategies & Mean & Std. Deviation \\
\hline Good explanation & 4.2150 & .68553 \\
\hline Manage to pull interest and attention & 4.1575 & .72734 \\
\hline Good communication skills & 4.1375 & .74160 \\
\hline Satisfied with teaching & 4.3275 & .68660 \\
\hline Give feedback and comments online & 4.2350 & .69713 \\
\hline Prepare notes early & 3.7850 & .89766 \\
\hline Provide announcement and update information & 4.1550 & .84425 \\
\hline Refer student to office when technical problems arise & 4.0925 & .70369 \\
\hline Give explanation online when needed & 3.5650 & .79205 \\
\hline Subject/course is overall satisfactory & 3.9600 & .78098 \\
\hline Notes given are suitable with course requirement & 4.0850 & .76107 \\
\hline Teaching is well structured & 4.2550 & .60902 \\
\hline Classroom and online learning blends effectively & 4.1575 & .65480 \\
\hline Blended mode program is fascinating & 3.9225 & .77975 \\
\hline Blended mode program helps me to upgrade my skills in school & 4.0825 & .70848 \\
\hline Blended mode program helps me to learn effectively & 4.0725 & .66960 \\
\hline Blended mode program gives positive impact & 4.0100 & .71846 \\
\hline Overall program is effective & 4.2100 & .62199 \\
\hline Total mean & 4.2650 & .62108 \\
\hline Attitude & 4.0350 & .55298 \\
\hline Satisfaction & 4.1357 & .49884 \\
\hline Strategies & 4.2014 & .49138 \\
\hline
\end{tabular}

Table 2: linear relationship between lecturer's attitude and teaching strategies towards student satisfaction

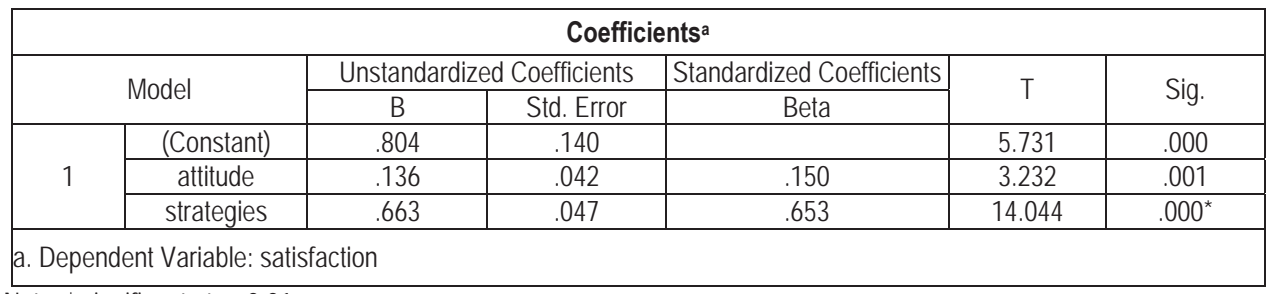

Note: * significant at $p<0.01$ 
Table 3: Variance explain of the model summary

\begin{tabular}{|c|c|c|c|c|}
\hline \multicolumn{5}{|c|}{ Model Summary } \\
\hline Model & R & R Square & Adjusted R Square & Std. Error of the Estimate \\
\hline 1 & $.769^{a}$ & .591 & .589 & .31986 \\
\hline a. Predictors: (Constant), strategies, attitude \\
\hline
\end{tabular}

Table 2.0 is derived from linear regression where attitude and strategies are independent variables and satisfaction is the dependent variable. A significant relationship at $p<0.01$ is shown in lecturer's strategies in teaching blended mode (face to face and e-learning) with student satisfaction. However, lecturer's attitude does not affect significantly on student satisfaction. This finding is consistent with finding by DeBourgh (1999) who found that pedagogy was the only predictor to student satisfaction which contributes to the variance explained. Table 3.0 provides the model summary where $76.9 \%$ variance of the model is explained by the teaching strategies. These results were compared to findings derived from the interviews conducted on two second year students; ( $n=1$ female and $n=1$ male). Interview questions were focused on the nature of lecturer-student interaction and lecturer's awareness in providing support for these students.

\subsection{Satisfaction in blended mode distant learning}

Satisfaction in learning depends highly on teaching strategies and lecturer's awareness in supporting students. The support includes providing good communication among lecturer and student; giving notes early and update information clearly. The quantitative finding indicate a strong relationship of teaching strategies and satisfaction $(B=.653)$. Based on the interviews, more information on the lecturer's attitude in giving support is discussed. Both interviewees were aware of the student-teacher interactions that took place in distance learning education. They frequently highlighted on the importance of further attention is needed in the two-ways interactions.

According to A1,

"I learnt the subject course from the lecturers... participate with the lecturers online. Not only through books but also the technology."

\section{According to B1,}

"it is easy to get notes from our lecturers, even information regarding our studies...but to certain extent it does not.. because sometimes it is not interactive for us to communicate with our colleagues and lecturers."

B1 relates to the notion that there has been a delay on the feedback given. Thus, sometimes he hopes for an immediate feedback whenever he needs immediate answer or help. Both of the interviewees view interaction differently. A1 relates to Learning Management System (LMS) as the means of communication. She is happy whenever she finds it easy to retrieve notes from LMS. However, B1 displays element of disappointment especially when it relates to LMS which according to him fails to allow students to interact with other students in forum section effectively. To ensure that an effective dialogue in an online learning environment, "each party in a dialogue is respectful and an active listener; each is a contributor, and builds on the contributions of the other party or parties" (Moore, 1993, p. 24). Thus, there were mix perceptions on the effectiveness of online communication. The former involves the system and the latter involves the lecturer. There have been many occasions whereby the lecturers treated and assisted their learners seriously. These include providing social network interaction in Facebook, to replace the forum in the LMS, create good rapport with the students by allowing students to communicate via phones and extending their time in the classroom to discuss any arising problems. To address the different learning styles of the distance learners, distant learning administrators and lecturers need to provide immediate feedback during the online communication process. As mentioned by Moore $(1993$, p.25) "by manipulating communications media, it is possible to increase dialogue between learners and their teachers, and thus reduce the transactional distance".

A1 is satisfied with the online academic support whereby she claims;

"It is like you are there with her alone, learning... it is satisfying."

She appreciates that she gets the personal (one to one) attention from the lecturers in answering to her academic enquiries via the LMS. Likewise in traditional classroom, there are many students who least get this type of attention. A1 
feels that when the lecturers are online, they are at their best in attending to the students' academic needs.

B1 however commented that;

"the LMS was always down... and the due date was over.."

"the lecturers who taught me... frequently use the LMS (160\%) and were also having similar problems with the system as they have uploaded the documents but we couldn't retrieve them from our document site."

In response to the technical problem, he would summon the technical staff from the academic affairs office. Lecturers were sometimes reluctance to be involved in the technical support issue as they were also having similar problems and were not competent enough to troubleshoot these technical problems.

Learning satisfaction is derived from the students' ability to be autonomous in learning. 'Learner autonomy is the extent to which the learner as opposed to the teacher is able to determine the goals, the learning experiences and the evaluation decisions of the learning programme" (Moore, 1993, p. 31). In distant learning environment, students can decide on the content, the experience and the evaluation criteria of their studies. However under the constraint where the curriculum content is compressed from the normal course outline, students can only be autonomous in terms of approaching the way they wish to study and from their own experience in the course they are taking. A1 asserted that;

\footnotetext{
"learning could be improvised by inviting all TESL4 students to participate in the forums and to ensure that every participation will rated fairly (marks) for their efforts."
}

This is due to the fact that she wants to have open discussions and help from friends or colleagues. B1 gave similar suggestions and recommended that

\begin{abstract}
"having an interactive section in the LMS would be very much.. celebrated by me because I need to regularly contact my group members and the lecturers ... to get clarifications or to clarify a few matters.. regarding my task may be I lacked in understanding certain matters..."
\end{abstract}

He also explains that

"we can't seem to be able to get together in the system..ie. the forum section.. once you have answered one forum, it is difficult to get others to reply or to partake in what you are saying."

\title{
4.2 Teaching strategies in distant education
}

Based on the descriptive statistics in Table 1.0, the results indicate that the mean scores are greater than 4.0 except for 'give immediate feedback online' with only 3.789. Thus, majority of the students did not show high agreement towards their lecturers in proving immediate feedback. Both students complained on the feedback given by the lecturers were very slow. Sometimes they waited far too long to get the response in the forum or quizzes. On the strategies of the lecturers, they responded:

\footnotetext{
'...we want experience lecturers to teach. We have problem with the foreigners or even the local lecturers who speak English most of the time'
}

\begin{abstract}
'however, when asked to explain in Malay language, they are willing to explain in Malay. Yet, all the notes are in English language, so it's a problem for us'
\end{abstract}

'The university should honour our own language'

'some lecturers said that we are adults, solve your own problems' 'too much assignment'

The positive feedback is:

'lecturers are good but there is no module'

Suggestions are made from both of the interviewees which include exam time table should not be scheduled during school period, and not too far from each subject. This is due to their working hours that they need to take leave 
from schools. Further, they have to come many times for the exam. They also request for;

i. Less subject for each semester

ii. Face to face classroom time should be extended

iii. Integrating Facebook is beneficial

iv. More classroom meeting is needed rather than just 3 to four times in a semester.

\subsection{Lecturer's attitude}

With respect to lecturer's attitude, the mean scores are greater than 4.0. This suggests high agreement in lecturer's positive attitude. Both interviewees seemed satisfied with their lecturers in terms of their abilities to display 'Good communication skills, Refer student to office when technical problems arise, Provide announcement and update information and Prepare notes early'. The lectures are aware of their responsibilities and the students gave two thumbs up when they were asked about the lecturer's attitude. Similar comments came from A1:

"learning at this University is the best experience I could ever have. The lecturers are friendly"

'lecturers prepare notes before coming to class'

'lecturer gives information in the LMS announcement'

B1 too agrees on the learning experience whereby he frequently comes in contact with good and friendly lecturers who are easily approachable. In short, the lecturers are able to create a warm learning environment which is adequately organized, structured, and flexible in that it encourages inquiry in the learning process (Starr-Glass, 2012).

\section{Discussion and conclusion}

This study has investigated student satisfaction and capturing their needs in the distant education via blended learning at the Government University in Malaysia. The quantitative findings indicate overall satisfaction in learning online and classroom face to face. However, a strong relationship between lecturer's teaching strategies and student satisfaction was captured. On the contrary, lecturer's attitude did not significantly affect the student satisfaction in learning. Parallel with Debourgh (1999)'s findings, pedagogy plays the most important role in promoting effectiveness in distant learning. When this study further dwelled on this issue, findings from the qualitative data indicated that the students were happy to study at the University via blended mode of distant education. They were persistent to learn despite the challenges of time, language, and being away from their families and the stressful working life. As they are adult learners, they expect the university authority to consider their plights seriously that is by considering their employer's needs when planning the examination schedule, allowed to register for minimum number subjects to be learnt for each semester, the use of mother tongue in daily classroom communication, provision of module for effective learning, extent the face to face classroom time and contact. They did not welcome too many group work assignment. They wanted to have only one assignment to focus on since there are too many subjects to be taken in a semester. As far as possible, the students request for three subjects only in a semester.

Despite the fact that e-learning emphasized heavily on communication and interactions (Moore, 1999; Ravenskroft, 2001), emerging themes derived from this study have shown factors affecting student satisfaction. These include number of assignments, schedule of exams, and number of subjects to be learnt in a semester. Immediate feedback and response do not only rely on the learning management system (LMS) but also on the lecturer's attitude in providing the means for communication. The LMS in the University seems to have many short comings such as limited access and space to frequent forum discussions, too time consuming to download files, and trouble shootings. Thus, the lecturer must be able to accommodate the short comings through integrating collaborative tools in communication which include chat room via Yahoo Messenger, Facebook and other social networks. Thus, high demanding work load among the lecturers who teach distant education need to be properly addressed by the University. Since online communication is crucial, the lecturers must at all times be ready to give feedback and response to students' grievances and problems in learning. Without effective communication and relationship with the lecturers, students are at lost and will not able to become full-fledged self-regulated learners. Self regulated learning involves less constrained learning environment (McGillivray, \& Castel, 2011). McGillivray relates the importance of self regulated learning as one of the conditions where older adult can efficiently learn to employ meta-cognitive strategies which enhance and enable them to recall selected information.

The findings indicate a strong implication on the theory of distant education where types of assignment and 
assessment need to be further examined. Further intervention from the university is needed in preparing notes or module for the learners' use. On the other hand, language may hinder and impede student motivation in becoming a persistent learner.

\section{References}

Areti, V. (2006). Satisfying distance education students of the Hellenic Open University. Ementor,2 (14), 1-12.

DeBourgh, G.A. (1999). Technology Is The Tool, Teaching Is The Task: Student Satisfaction In Distance Learning. In J. Price et al. (Eds.), Proceedings of Society for Information Technology \& Teacher Education International Conference 1999 (pp. 131-137). Chesapeake, VA: AACE. Retrieved from http://www.editlib.org/p/7521

Moore, M. G. (1993). Theory of transactional distance. In D. Keegan (Ed.) Theoretical principles of distance education (Vol. 1, pp. 2238). London: Routledge.

Vygotsky,L. (1978). Interaction between learning and development. From Mind and Society. Cambridge, M.A. Harvard University Press.

Mahmod, Razmah.; Dahlan, Noornin.; Ramayah, T; Karia. Noorliza and Muhamad Hasmi. Attitudinal Belief on the Adoption of e-MBA Program in Malaysia

Turkish Online Journal of Distance Education (TOJDE), April 2005, 6(2), pp 115-124

Wright, Clayton R. (n. d.) Criteria for Evaluating the Quality of Online Courses. Grant MacEwan College Instructional Media and Design. http://www.imd.macewan.ca/imd/content.php?contentid=36

Walker, S. L. (2005). Development of the Distance Education Learning Environments Survey (DELES) for higher education. The Texas Journal of Distance Learning, 2 (1), 1-16.

Lee, Jong-Ki and Lee, Woong-Kyu (2008). The relationship of e-Learner's self-regulatory efficacy and perception of e-Learning environmental quality. Computers in Human Behavior, Vol.24(1),pp.32-47.

Khadijah Abdul Rahman, Siti Aswani Mohd Ghazali, Dr Mohd Nasir Ismail The Effectiveness of Learning Management System (LMS) Case Study at Open University Malaysia (OUM), Kota Bharu Campus. Journal of Emerging Trends in Computing and Information Sciences, Vol. 3(10).

McGillivray, S., \& Castel, A. D. (2011). Betting on memory leads to metacognitive improvement in younger and older adults. Psychology and Aging, 26, 137-142.

Ravenskroft, A. (2001). Designing E-learning interactions in the $21^{\text {st }}$ century: revisiting and thinking the role of theory. European Journal of Education, Vol.36(2). 